\title{
O texto em ambientes de bibliotecas digitais: uma análise dos elementos da narrativa digital
}

Text in digital library environments: An analysis of the elements of digital narrative

\author{
Juliane Vargas Nunes, Berenice Santos Gonçalves
}

ambiente digital, narrativa digital, texto digital

No ambiente digital o texto assume novas formas a partir do uso de recursos midiáticos e interativos próprios desse ambiente, que possui capacidade narrativa. Diante da emergência de textos e bibliotecas digitais surge a necessidade de se investigar como os elementos da narrativa digital podem oferecer uma experiência mais engajada, envolvente e prazerosa. Assim, este artigo propõe uma análise descritiva de uma biblioteca digital, a partir da taxonomia para narrativas digitais proposta por Paul (2010). Os resultados da análise indicaram que os elementos da narrativa digital que a biblioteca melhor explora são contexto e comunicação. Também emprega de forma efetiva o relacionamento nos conteúdos organizados de forma não-linear. Porém, explora de forma limitada os elementos mídia e ação.

digital environment, digital storytelling, digital text

In the text digital environment takes on new forms from the use of media and interactive features that own environment, which has narrative ability. Against the emergence of texts and digital libraries there is a need to investigate how the digital narrative elements can provide a more engaging experience, engaging and enjoyable. Therefore, this paper proposes a descriptive analysis of a digital library, based on taxonomy for digital narratives proposed by Paul (2010). The results of the analysis indicate that the elements of the digital narrative that exploits the best library are context and communication. Also employs effectively the relationship, the organized content of non-linear fashion. However, explores a limited extent the media and action elements.

\section{Introdução}

A inserção dos computadores afetou todos os tipos de mídia tornando-as compatíveis entre si, independente do suporte (SANTAELLA, 2013). O conteúdo impresso foi o primeiro a sofrer um intenso processo de digitalização com o projeto Xanadu, liderado por Ted Nelson (TORACI, 2012). Inicialmente esses materiais se limitavam a cópias digitalizadas dos materiais impressos. Atualmente utilizam diversas mídias e recursos de interação e se apresentam em diferentes formatos de arquivo.

Contudo, segundo Toraci (2012), para além do desenvolvimento de tecnologias que permitam a geração ou a codificação de conteúdos em linguagem digital, o desafio reside no seu armazenamento e formas de acesso organizado. Segundo Wurman (2005), a maneira 
confusa e desorganizada como grande parte dos conteúdos são apresentados na internet faz com que muitos deles se mostrem inúteis para as pessoas.

Assim, Adipat, Zhang e Zhou (2011) apontam que a organização de um texto influencia o modo como os leitores adquirem, lembram e usam suas informações. Segundo os autores, quando uma pessoa navega em uma página da Web, por exemplo, tende a confiar na estrutura hierárquica do conteúdo, concentrando-se nas categorias e informações para imediatamente entender o conteúdo global e sua estrutura.

Considerando também o tipo do texto, Zumbach e Schwartz (2014), acreditam que apresentar um conteúdo com enredo linear e cronológico, como uma narrativa, na forma de um hipertexto, aumenta a carga de memória de trabalho, pois exige que o leitor reconstrua essa linearidade. Mesmo motivo pelo qual Nielsen e Budiu (2014) defendem que é mais fácil ler um texto de ficção em um dispositivo móvel do que um texto de negócios ou outros de não ficção.

\section{Texto no ambiente digital}

Segundo Lupton (2006), no meio digital, textos longos são geralmente divididos em pedaços que podem ser acessados por meio de mecanismos de busca ou links de hipertexto. Com o auxílio desses recursos próprios do ambiente digital, o leitor pode localizar uma informação específica ou processar rapidamente um volume de conteúdo para dele extrair informações imediatamente. Além da possibilidade de acesso a outras fontes de informação, a partir de links externos.

Lupton (2006) aponta que o texto digital se utiliza de estratégias de Design comuns ao meio impresso, especialmente aquelas aplicadas aos livros, como índices, apêndice e notas de rodapé, com o objetivo de orientar e oferecer alternativas durante o processo de leitura, diante da linearidade do discurso. Contudo, também se apropria também de recursos próprios do meio digital, otimizando essas estratégias como, por exemplo, o acesso às notas de rodapé a partir de links internos.

Outro exemplo de ruptura da linearidade no meio digital é a base de dados, um sistema de elementos que pode ser rearranjados em incontáveis sequências, que oferecem inúmeras opções a leitores e escritores. Elas são a base dos jogos eletrônicos, revistas e catálogos, gêneros que criam um espaço informacional, e também para as bibliotecas digitais que atuam como espaços virtuais de acesso a diversas fontes de conhecimento (LUPTON, 2006).

\section{Ambientes digitais: propriedades e narrativas}

De acordo com Murray (2003), os ambientes digitais possuem capacidade narrativa quando compreendidos para além do conceito de multimídia como associação/justaposição de mídias. Assim, aponta quatro principais propriedades dos computadores que, separada e coletivamente, fazem dele um poderoso veículo para criação literária, sendo elas: procedimental, participativa, espacial e enciclopédica.

A exploração dos recursos multimídia é um processo natural que surge da necessidade de superar os formatos tradicionais (MURRAY, (2003). Contudo, para a autora os ambientes digitais ainda são mal explorados na construção de narrativas, pois focam os recursos multimídia e não o enredo em si. Paul (2010) também acredita que a maior parte dos materiais digitais utiliza convenções ultrapassadas que não exploram efetivamente as propriedades dos ambientes digitais. Por isso, propõe uma taxonomia de narrativas digitais no âmbito das notícias online, que utilizam elementos de outras mídias em uma combinação própria. Esses elementos se dividem em cinco categorias: mídia, ação, relacionamento, contexto e comunicação.

A mídia diz respeito ao tipo de expressão usada na criação e roteiro da narrativa e seu suporte. Precisa ser examinada sob quatro elementos: configuração, tipo, fluxo e tempo/espaço. A configuração especifica se as mídias são usadas individual ou conjuntamente e a relação entre elas. O tipo define a mídia utilizada. O fluxo considera se o conteúdo é gravado ou ao vivo. E o tempo/espaço especifica se o conteúdo foi ou não alterado. 
A ação se refere a dois aspectos: ao movimento do próprio conteúdo, que pode ser dinâmico ou estático, e à ação requerida ao usuário para acessar o conteúdo, que pode ser ativa ou passiva. A ação prevê a possibilidade de diferentes combinações entre esses aspectos que podem mudar ao longo da interação.

O relacionamento, que ocorre entre usuário e sistema, pode ser: fechado quando $o$ conteúdo só pode ser lido/assistido/ouvido e aberto quando pode ser manipulado. Essa abertura pode ser classificada em: linear/não linear, customizável/padrão, calculável/não calculável, manipulável/fixo e expansível/limitado. É linear quando não permite alterar a ordem das partes do conteúdo. É customizável quando se adapta às preferências do usuário. É calculável quando possibilita o registro de respostas do usuário. É manipulável quando permite movimentar as suas partes. É expansível quando permite que o usuário insira dados.

O contexto se refere ao conteúdo dos links, que podem ser: auto-explicativo/hipermidiático, embutido/paralelo, interno/externo, suplementar/ duplicativo e contextual/relacionado. É autoexplicativo quando o link está relacionado ou é relevante para a narrativa e hipermidiático quando é adicional. É embutido quando o link está dentro da narrativa principal e paralelo quando está ao seu lado. O link interno se dirige para um material criado ou mantido pelo site e o externo para fora dele. O link suplementar traz material inteiramente diferente do conteúdo, ao contrário do link duplicativo. O link contextual fornece material específico para a narrativa enquanto o relacionado oferece conteúdo similar.

Já a comunicação, que se dá entre usuários, se divide em cinco aspectos: configuração, tipo, direcionamento, moderação e objetivo. A configuração pode ser de um-a-um, um-paravários, vários-para-um e muitos-para-muitos. O tipo pode ser bate-papo, email, SMS, etc. O direcionamento pode ser ao vivo ou gravado. A moderação diz respeito a supervisão ou não sobre a comunicação. E o objetivo pode ser troca de informações, registro e comércio.

Contudo, segundo Paul (2010), é preciso saber quais desses recursos se mostram mais apropriados para determinada narrativa, oferecendo assim uma experiência mais engajada, envolvente e prazerosa, ou seja, mais completa para o usuário. Assim, este artigo propõe uma análise descritiva da biblioteca Literatura Digital ${ }^{1}$, a partir da taxonomia proposta por Paul (2010), tendo como foco a apresentação do texto e não as qualidades ergonômicas do sistema, conforme fazem grande parte das pesquisas atuais.

\section{Procedimentos metodológicos}

Os procedimentos metodológicos foram estruturados em três principais etapas, a saber: 1. Caracterização do objeto de estudo, 2. Processo de análise e 3. Resultados e discussões.

\section{Etapa 1: Caracterização do objeto de estudo}

A Literatura Digital é a maior biblioteca digital de literatura brasileira e portuguesa aberta e gratuita existente. Foi elaborada pelo Núcleo de Pesquisa em Informática, Literatura e Linguística - NUPILL e pelo LAPESD - Laboratório de Pesquisa em Sistemas Distribuídos, ambos vinculados a Universidade Federal de Santa Catarina - UFSC. Tem como objetivo criar um ambiente de leitura e ensino-aprendizagem de literatura (NUPILL, 2012).

Além da consulta às obras digitalizadas disponibiliza um catálogo com dados biobibliográficos de autores brasileiros e portugueses, assim como documentos do acervo pessoal de alguns autores do Estado de Santa Catarina. Mediante cadastro oferece a adição de comentários e uma ferramenta de anotações, o DL Notes, que permite a inclusão de anotações em cada obra, que ficam disponíveis para o usuário em seus próximos acessos, independente do dispositivo e podem ser públicas ou privadas.

Em sua tela inicial (ver Fig. 1), a biblioteca apresenta uma lista com as obras mais acessadas e as últimas cadastradas, notícias relacionadas ao NUPILL, acesso ao Portal Santa Catarina, que disponibiliza textos literários catarinenses. Oferece opções de pesquisa simples, por documento, por autor e por conteúdo de todas as obras

\footnotetext{
${ }^{1}$ Disponível em: http://www.literaturabrasileira.ufsc.br/. Acesso em: 11/03/2015
} 
cadastradas; e também apresenta todas as obras cadastradas, divididas por nome do autor, do documento ou do acervo.

Figura 1 - Tela inicial da Literatura Digital. Fonte: http://www.literaturabrasileira.ufsc.brl. Acesso em: 11/03/2015.Figura

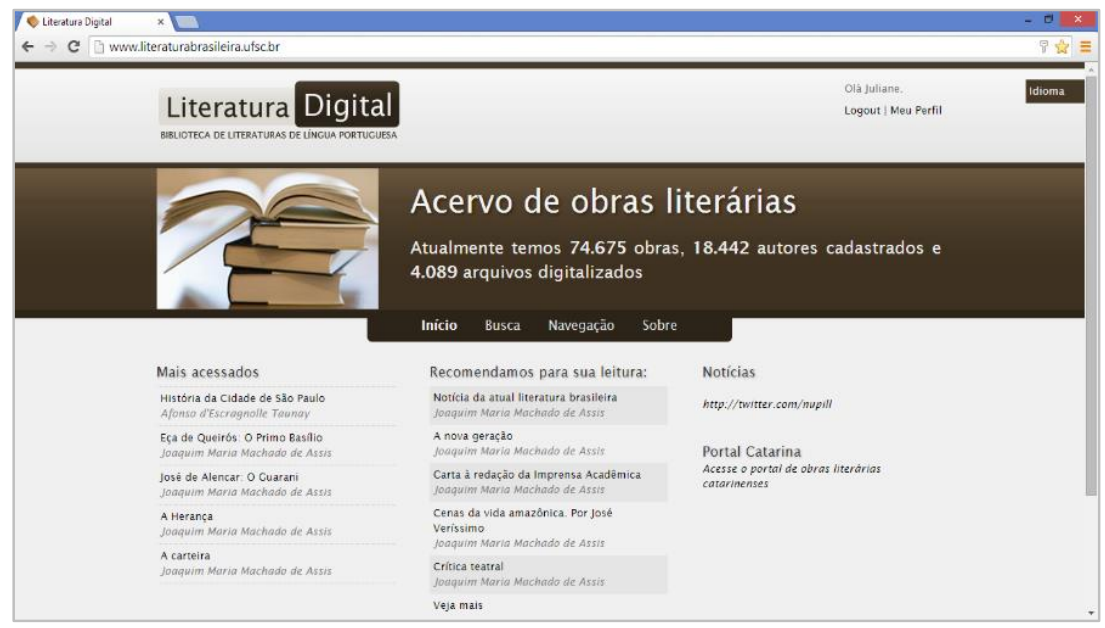

Cada obra apresenta informações sobre autor, gênero, tipo, fonte, editora e fatos históricos a ela relacionados. Algumas obras estão em formato html e outras em pdf. As obras em pdf que são divididas em capítulos, edições ou fascículos oferecem acesso individual às suas partes. Já aquelas que são divididas e estão em html, permitem o acesso às suas partes, a partir de links vinculados a um sumário ou ao conteúdo completo, a partir da barra de rolagem.

Etapa 2: Processo de análise

A análise foi realizada em outubro de 2014, a partir de um computador, já que a não adequação do conteúdo da biblioteca Literatura Digital ao tamanho da tela dificultaram seu acesso a partir de dispositivos móveis. Para a análise foi utilizado um formulário que apresentava a taxionomia proposta por Paul (2010) na forma de questões.

\section{Resultados e discussões}

A partir da taxonomia de Paul (2010), a análise da biblioteca Literatura Digital apontou as questões:

\section{Elemento 1: Mídia}

Possui conteúdo de mídia individual, do tipo texto, com fluxo gravado, ou seja, elaborado anteriormente à sua visualização. Os textos literários não possuem edição. Mas as informações sobre documentos e autores, fatos históricos relacionados, dentre outras, foram elaboradas pelos pesquisadores vinculados ao NUPILL, a partir de diferentes fontes de referência.

\section{Elemento 2: Ação}

Seu conteúdo é estático e ativo, pois não possui movimento e depende da interação do usuário para ser acessado. As informações presentes na tela inicial são acessadas a partir de links e itens de menu, assim como nas páginas secundárias. Porém, a maior parte dos arquivos com as obras literárias depende exclusivamente do uso de rolagem para ser visualizada, exceto naqueles que possuem sumário.

\section{Elemento 3: Relacionamento}

Em geral, seu conteúdo é não-linear, pois cabe ao usuário decidir que informações acessar e em que ordem, assim como nas obras literárias que possuem sumário. Contudo, nas obras sem sumário o conteúdo é linear. Seu conteúdo é padronizado, pois não oferece capacidade de customização. Não é manipulável, pois não permite a movimentação de suas partes. É expansível pela possibilidade de anotação, oferecida pelo DL Notes. 


\section{Elemento 4: Contexto}

Possui uma narrativa hipermidiática pois seus links dão acesso a materiais relacionados a narrativa principal. Grande parte desses links são paralelos, pois estão localizados ao lado do texto principal, exceto aqueles das obras com sumário que são embutidos. Esses links são tanto internos (sumário, arquivo da obra digitalizada) e externos (Notícias, Portal Catarina), mas todos são suplementares pois dão acesso a informações diferentes do exposto. Os links do sumário e dos arquivos das obras literárias são contextuais, pois são dão acesso a conteúdos específicos para a narrativa. Já os links do Portal Catarina e Notícias são relacionados, pois oferecem informações similares.

\section{Elemento 5: Comunicação}

Oferece comunicação um-a-um pelo link de email e um para vários a partir dos comentários, da resposta a uma anotação pública no DL Notes (ver Fig. 2) e da recomendação no Facebook, todos com direcionamento gravado. Sua comunicação não possui moderação pois todas os comentários e anotações são publicados independente de avaliação prévia e tem como objetivo a troca de informações.

Figura 2 - Tela de resposta a uma anotação no DL Notes. Fonte: http://www.literaturabrasileira.ufsc.br/. Acesso em: $11 / 03 / 2015$.

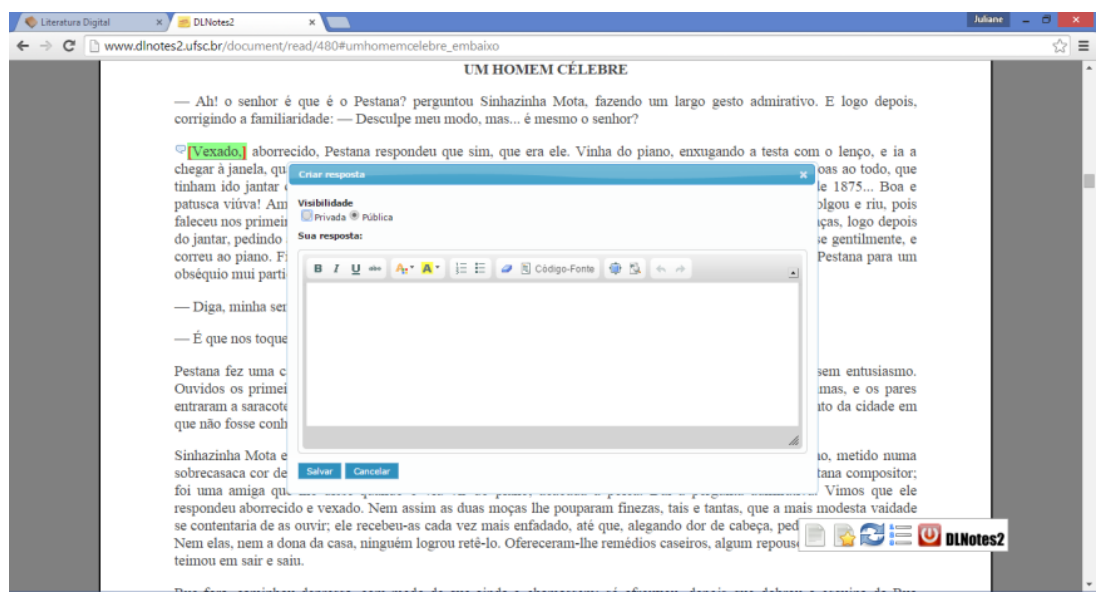

A partir dos dados, é possível identificar que em termos de mídia, relacionada com propriedade enciclopédia dos ambientes digitais no armazenamento e recuperação dos arquivos (MURRAY, 2003), a biblioteca utiliza apenas texto escrito. Ademais, utiliza conteúdo exclusivamente gravado e, no caso das obras literárias, não editado. Opções que provavelmente tenham relação com o tipo de conteúdo que oferece, essencialmente textual e com caráter documental. Isso fica evidente nas obras literárias disponibilizadas como imagem do livro impresso, em formato pdf.

Contudo, esses arquivos pdf se tornam especialmente difíceis de visualizar em dispositivos pequenos, pois dependem do uso constante de zoom e rolagem. Isso, associado à não adequação do conteúdo da biblioteca Literatura Digital ao tamanho da tela fere os princípios do Design Responsivo. Nesse sentido, a biblioteca deixa de explorar a propriedade procedimental dos ambientes digitais (MURRAY, 2003). Ademais, o uso exclusivo do texto limita o acesso do conteúdo a pessoas videntes. Assim, a propriedade enciclopédica poderia ter sido melhor explorada se também fossem utilizadas outras mídias como, por exemplo, o áudio.

Quanto a ação, que se utiliza principalmente da propriedade participativa dos ambientes digitais na interação entre usuário e conteúdo, identifica-se a presença exclusiva do texto estático e passivo, embora a ação permita diferentes combinações entre esses aspectos que podem mudar ao longo da interação.

Quanto ao relacionamento, favorecido sobretudo pelas propriedades participativa e espacial dos ambientes digitais que atuam sobre a interação entre usuário e conteúdo e a exploração dos espaços navegacionais (MURRAY, 2003), percebe-se uma organização predominantemente linear do conteúdo das obras literárias. 
Por outro lado, o uso do sumário, presente em algumas obras, oferece acesso imediato às diferentes partes do conteúdo, como alternativa à organização linear. Assim como os itens Busca e Navegação que oferecem mais de um caminho de acesso a obra. Nesse sentido, as propriedades participativa e espacial dos ambientes digitais (MURRAY, 2003) seriam melhor exploradas se o sumário estivesse disponível em todas as obras.

Já o contexto, que utiliza principalmente a propriedade enciclopédica na conexão entre os conteúdos (MURRAY, 2003), permite que a biblioteca disponibilize uma grande quantidade de informações, a partir de links internos e externos. Assim, esta é uma propriedade fundamental para a biblioteca. Os links internos disponibilizam conteúdos próprios, essenciais para a narrativa, sobretudo as obras. Já os externos oferecem conteúdos similares.

Por fim, a comunicação ocorre sob duas vias: entre usuários e administradores do conteúdo da biblioteca, a partir de email e comentários; e entre usuários, a partir de comentários, anotação pública no DL Notes e recomendação no Facebook. Essas ferramentas corroboram a proposta da biblioteca como ambiente de leitura e ensino-aprendizagem de literatura, permitindo a troca de informações. Dentre elas, destaca-se a ferramenta DL Notes como mecanismo de comunicação e apoio à leitura.

A partir desses dados é possível identificar que os elementos da narrativa digital que a biblioteca Literatura Digital melhor explora são o contexto e a comunicação (PAUL, 2010). Também emprega de forma efetiva o relacionamento, nos conteúdos organizados de forma não-linear. Por outro lado, explora de forma limitada os elementos mídia, ação e também o relacionamento nos conteúdos organizados linearmente.

Por consequência, a propriedade dos ambientes digitais que a biblioteca melhor explora é a enciclopédica (MURRAY, 2003). Explora parcialmente as propriedades participativa e espacial nas interações entre usuário e conteúdo e nos espaços navegacionais. Contudo, não explora a propriedade procedimental.

\section{Considerações finais}

A partir da análise foi possível identificar que os ambientes digitais possuem propriedades que possibilitam a exploração de elementos específicos das narrativas digitais em ambientes como a biblioteca Literatura Digital. Contudo, em função de sua natureza, esses ambientes possuem características específicas que interferem na forma de apresentação de seu conteúdo e interação com o usuário.

Nesse sentido, muitas das soluções adotadas pela biblioteca se mostram coerentes como o uso de texto escrito e não editado e a oferta de meios de comunicação entre usuários. Algumas delas limitam a exploração de elementos da narrativa digital (PAUL, 2010) e das propriedades dos ambientes digitais (MURRAY, 2003) em detrimento de outros benefícios. Um exemplo é o uso exclusivo de texto estático e passivo, que não explora todo o potencial da propriedade participativa, mas pode facilitar a leitura de textos mais extensos.

Por outro lado, algumas dessas soluções podem trazer dificuldades para a interação como a falta de acessibilidade decorrente do uso exclusivo de texto e a grande quantidade de rolagem necessária para a visualização do conteúdo em algumas obras. Assim como a não adequação do conteúdo da biblioteca aos diferentes tamanhos de tela, resultante da não aplicação dos princípios do Design Responsivo e, consequentemente, da propriedade procedimental dos ambientes digitais.

Portanto, sem desconsiderar sua natureza, é importante que ambientes como a biblioteca de Literatura Digital explorem os elementos das narrativas digitais, a partir das propriedades dos ambientes digitais, visando ampliar as possibilidades de leitura. Assim, precisam incluir uma demanda recente mas promissora de leitores de textos literários em dispositivos móveis.

\section{Referências}

ADIPAT, Boonlit; ZHANG, Dongsong; ZHOU, Lina. The effects of Tree-View based presentation adaptation mobile web browsing. Mis Quarterly, Minneapolis, v. 35, n. 1, p.99-121, mar. 2011. 
TORACI, Viviane. Bibliotecas Digitais como objetos das novas mídias: Sugestões de melhoramentos para acesso e manipulação de conteúdos. In: XIV Congresso de Ciências da Comunicação na Região Nordeste, 2012, Recife. Anais... São Paulo: Intercom, 2012. p. 1-13.

ZUMBACH, Joerg; SCHWARTZ, Neil. Hyperaudio learning for non-linear auditory knowledge acquisition. Computers In Human Behavior, v. 41, n. 12, p.365-373, dez. 2014.

Livros, e material não publicados

MURRAY, Janet. Da Forma Aditiva para a Expressiva. In: MURRAY, Janet. Hamlet no Holodeck: O futuro da narrativa no ciberespaço. São Paulo: Itaú Cultural/Unesp, 2003. Cap. 3. p. 73-97.

NIESEN, J.; BUDIU, R. Usabilidade Móvel. Elsevier: Rio de Janeiro, 2014.

PAUL, Nora. Elementos das narrativas digitais. In: FERRARI, Pollyana. Hipertexto e Hipermídia. São Paulo: Contexto, 2010.

SANTAELLA, Lucia. Comunicação Ubíqua: repercussões na cultura e na educação. São Paulo: Paulus, 2013.

WURMAN, R. S. Ansiedade de informação2: um guia para quem comunica e dá instruções. São Paulo: Cultura, 2005.

Textos publicados na internet

NUPILL (Santa Catarina). Sobre a Biblioteca de Literaturas de Língua Portuguesa. 2012. Disponível em: <http://www.literaturabrasileira.ufsc.br/sobre/>. Acesso em: 04 nov. 2014.

\section{Sobre as autoras}

Juliane Vargas Nunes, Doutoranda, UFSC, Brasil <julivn@gmail.com> Berenice Santos Gonçalves, Doutora, UFSC < $\underline{\text { berenice@cce.ufsc.br> }}$ 